\title{
POSSIBLE POLYPLOIDY IN THE HYMENOPTERA
}

\author{
By SHELdON C. REED
}

Bussey Institution, Harvard University

The Bresslau-Harnisch lists of animal chromosome numbers (Tab. Biol. 4) include data for the twenty species of Hymenoptera whose chromosome numbers were known at that time. Records subsequently published give the numbers in two additional species, Habrobracon juglandis and Pteronidea ribesii. The total may be summarized in this fashion:

\begin{tabular}{rrrrr}
1 & species, haploid & number & 4 \\
8 & “ & “ & “ & 8 \\
\hline 1 & “ & “ & “ & 9 \\
3 & “ & “ & “ & 10 \\
5 & “ & “ & 12 \\
3 & “ & “ & “ & 16 \\
1 & “ & “ & “ & 24
\end{tabular}

Eighteen of the twenty-two species have chromosome numbers of 4 or a multiple of 4 ; whereas only four species have different chromosome numbers (9 or 10). These numbers are representative of seven families out of more than one hundred in the Hymenoptera and seem to be a random sample of what may be expected to be the situation in the other species whose chromosome numbers are yet unknown. Though the number of species which have been investigated is very small, the idea suggests itself that these chromosome numbers may be a result of polyploidy such as is known to occur in plants. 
There is very good evidence that about half of the Angiosperms are polyploids. From such studies as those reviewed by Darlington (Darlington's Cytology, p. 212) we see that in polyploid series one finds many species with double the basic chromosome number, fewer with the number obtained by a second doubling and still fewer resulting from further doublings of the basic number. Such would seem to be the case even in this small sample from the Hymenoptera. A second point also demonstrated by the abundant plant material is that in polyploid series there are few species with prime numbers as their haploid count. In the Hymenoptera there are no species with prime numbers. If the chromosome numbers in the order were entirely fortuitous, one should expect several species to show prime numbers as their haploid count.

The rareness of polyploidy in the animal kingdom and particularly in diœcious species has been considered to be due, at least in part, to the fact that such species are in one sex heterozygous for the sex chromosomes. Multiples of the chromosomes in the vast majority of animals would thus cause an upset of the balance between sex chromosomes and the autosomes as was suggested by Muller (Am. Nat. 59) in regard to polyploidy. He suggests, however, that polyploidy might occur in the Hymenoptera.

In the Hymenoptera it may have been possible to avoid this difficulty since they are almost unique among insects in that their males are haploid. Thus if there is any order of insects in which polyploidy is possible it would seem to be the Hymenoptera.

The suggestion that the series of chromosome numbers in the Hymenoptera may have arisen by polyploidy rests, then, on these considerations: 1 , all but four of the species have chromosome numbers which are 4 or a multiple of four; 2 , the existence of haploid males may have allowed polyploidy to occur. 

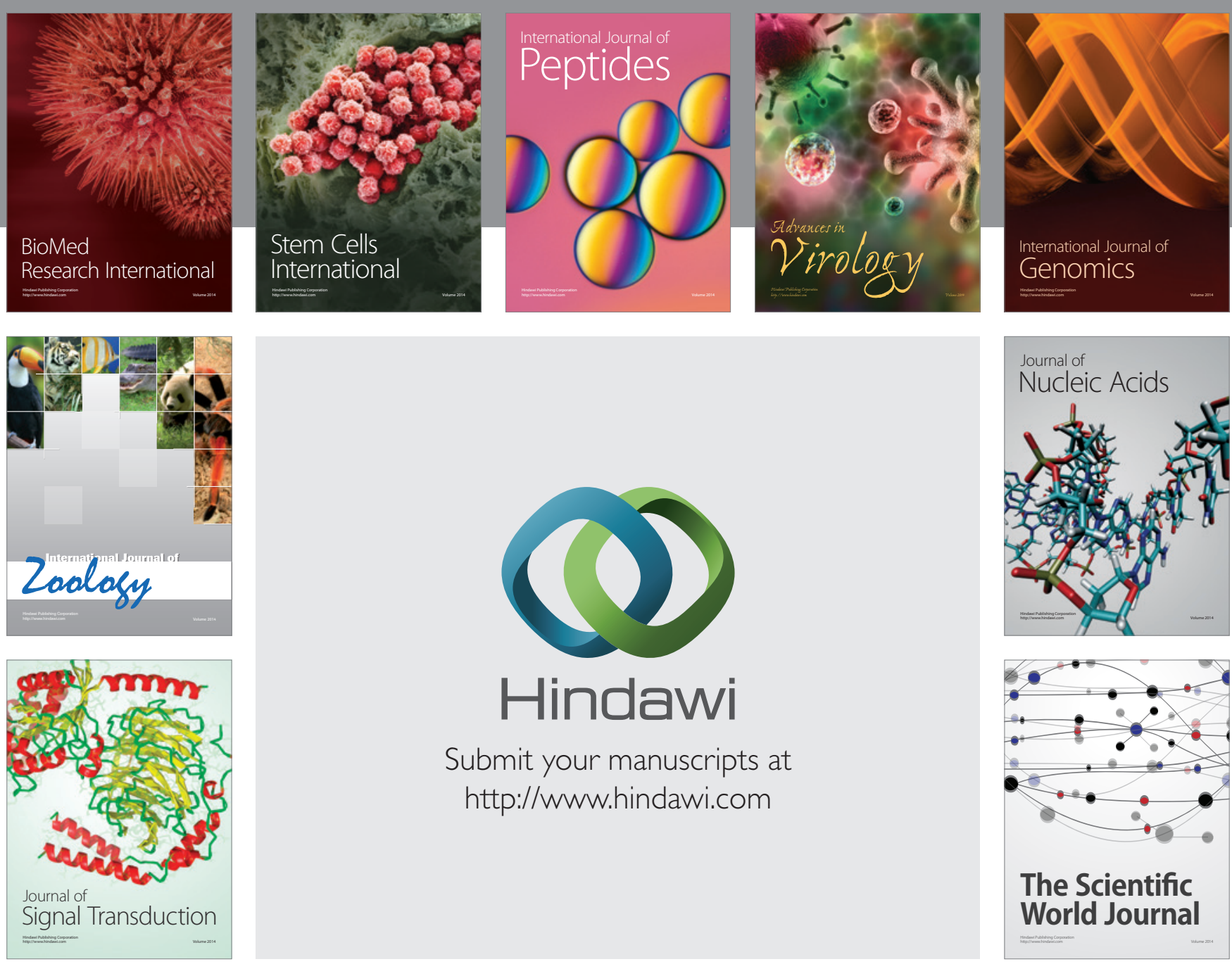

Submit your manuscripts at

http://www.hindawi.com
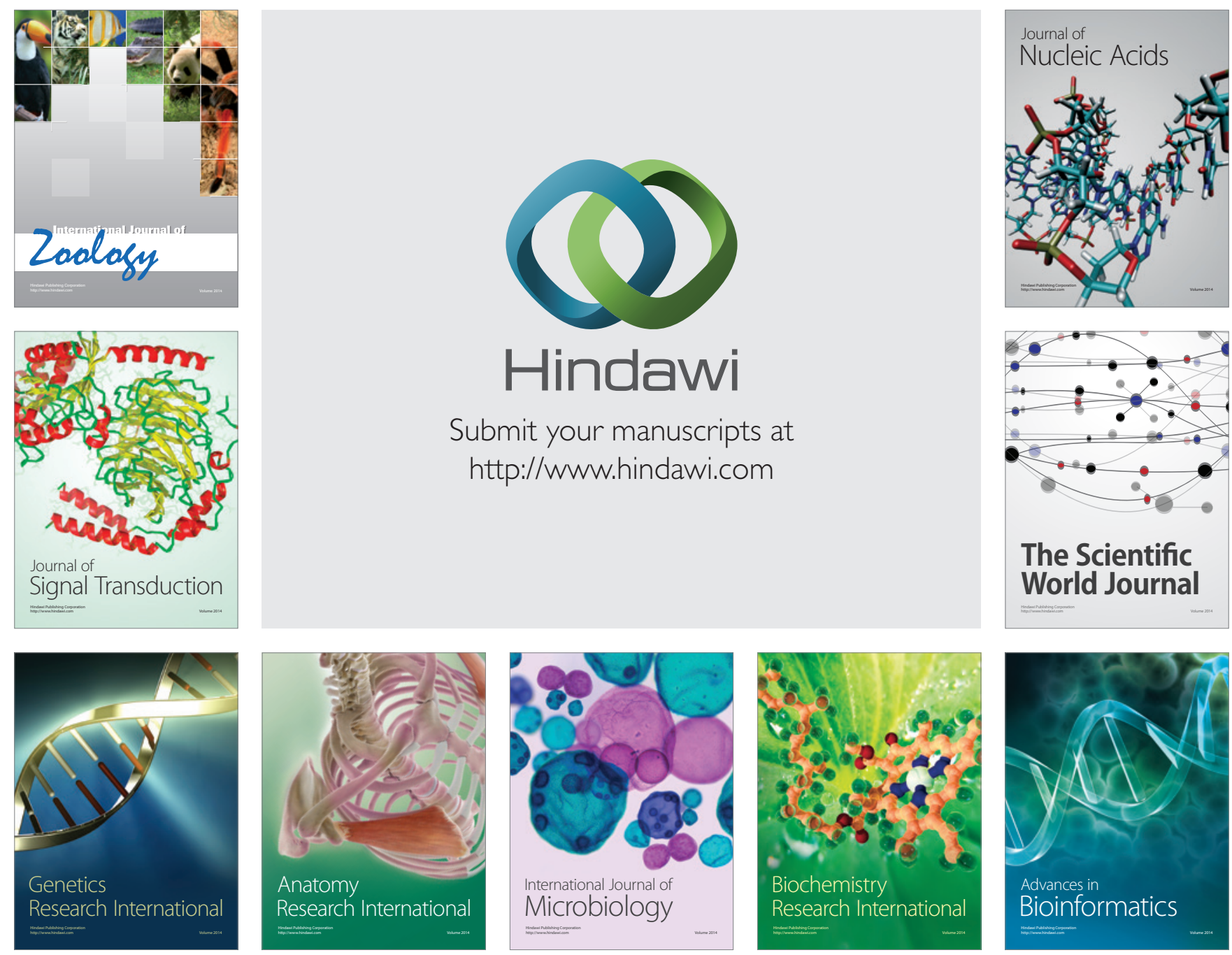

The Scientific World Journal
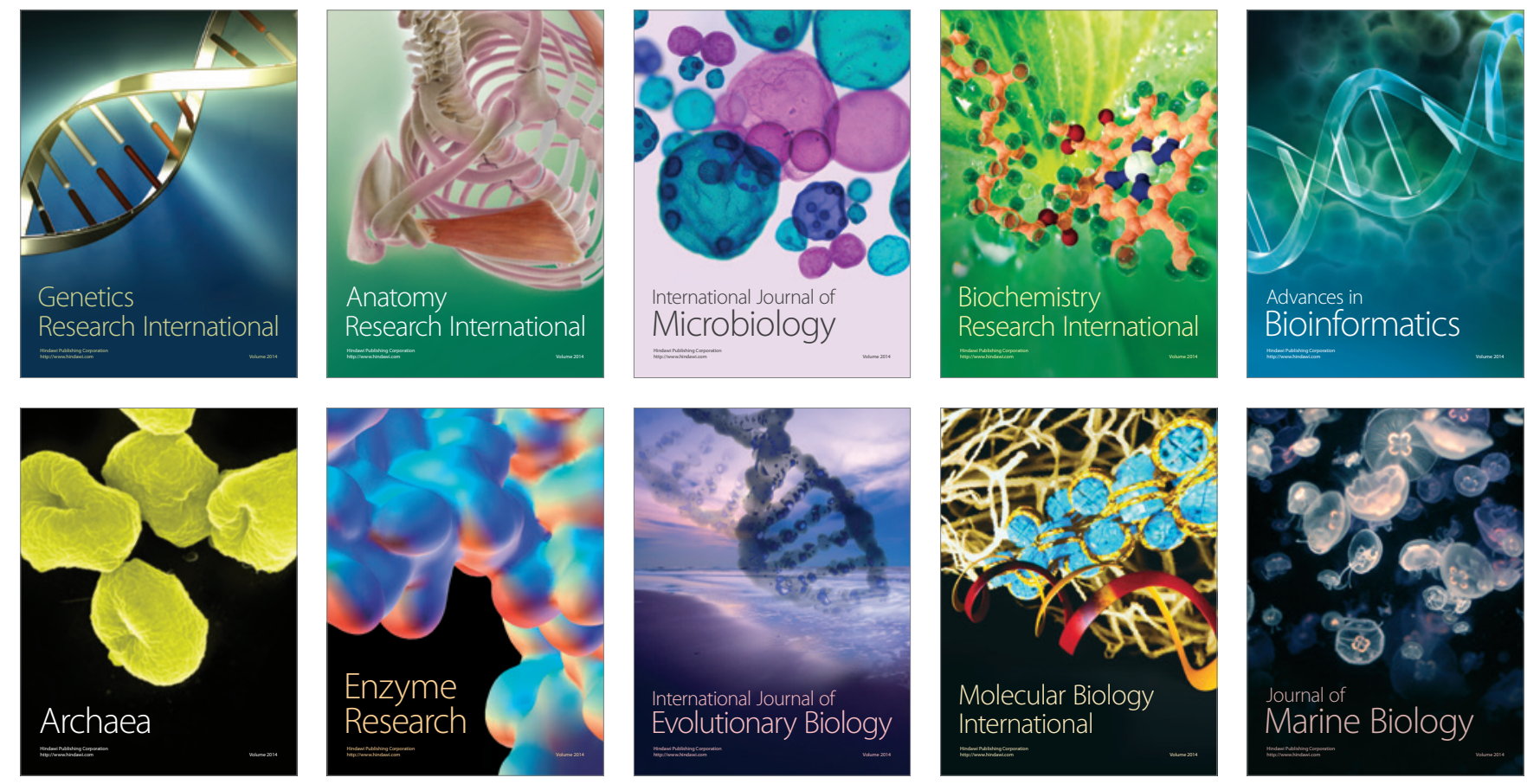